\title{
MAPEAMENTO E CARACTERIZAÇÃO DOS REMANESCENTES DE DUNAS DO MUNICÍPIO DE NATAL - RN, BRASIL
}

\author{
Carolina Maria Cardoso Aires Lisboa ${ }^{1}$; Uilton Magno Campos $^{2}$; Simon Klecius Silva de Souza ${ }^{3}$
}

(recebido em 11.01.2011 e aceito para publicação em 15.09.2011)

\section{RESUMO}

A duna é um ecossistema especial, constituído por areias quartzosas que, quando depositadas pela ação do vento dominante, formam montes móveis que são posteriormente colonizados por plantas e animais típicos de regiões com baixo índice de pluviosidade. São excelentes reservatórios de água doce, sobretudo para a recarga dos aquíferos, uma vez que as águas pluviais que penetram acumulam-se facilmente no solo. Esses espaços são bastante frágeis, especialmente em áreas urbanas, sujeitos a formar áreas de risco pela movimentação de areia caso não sejam devidamente conservados. Em Natal - RN foi realizado o levantamento e a caracterização dos remanescentes de dunas não inseridos em Zonas de Proteção Ambiental ZPAs, utilizando-se ferramentas de geoprocessamento e estudos de campo. Constatou-se que Natal possui 46 remanescentes, a maioria sujeita à grande pressão urbana, cobrindo aproximadamente $2,5 \%$ de seu território e distribuídos proporcionalmente em relação à dimensão das Regiões Administrativas. Desses, 25 estão no entorno de Zonas de Proteção Ambiental - ZPAs e mantêm características semelhantes a elas, devendo ser incorporados. Ações para manutenção deste ecossistema nativo são necessárias e urgentes. Para tanto, foram elaboradas recomendações de uso e ocupação para cada área como metas de planejamento urbano e ambiental.

1. Bióloga, mestre em Ciências Biológicas pela UFRN. Setor de Projetos e Planejamento Urbano e Ambiental da Secretaria Municipal de Meio Ambiente e Urbanismo - SEMURB, Natal, RN, carolisboabio@yahoo.com.br.

2. Tecnólogo em Gestão Ambiental pelo IFRN. Setor de Projetos e Planejamento Urbano e Ambiental da SEMURB, Natal, RN, uiltonmagno@ig.com.br.

3. Tecnólogo em Gestão Ambiental pelo IFRN. Especialista em Geoprocessamento e Cartografia Digital pela UFRN, Setor de Projetos e Planejamento Urbano e Ambiental da SEMURB, Natal, RN, simon.klecius@natal.rn.gov.br.

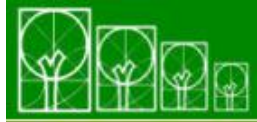

$\mathbf{S} \cdot \mathbf{B} \cdot \mathbf{A} \cdot \mathbf{U}$ Soc. Bras. de Arborização Urbana 
Palavras-chave: Planejamento Urbano e Ambiental; Áreas de Preservação Permanente; Geoprocessamento; Zoneamento Ambiental; Gestão de Áreas Verdes.

\section{MAPPING AND CHARACTERIZATION OF REMNANTS OF DUNES IN NATAL - RN, BRAZIL}

\section{ABSTRACT}

The dune is a special ecosystem, consisting of quartz sand which, when deposited by action of dominant winds, shapes moving mounds that are later colonized by plants and animals typical of regions with low rainfall. They are excellent freshwater reservoirs, especially for aquifers recharge, once the rainwater easily penetrates the soil. These spaces are quite fragile, especially in urban areas, because they form risk areas caused by the moving sands, if not properly maintained. In Natal municipality, Brazil, a survey was carried out with the remnants of dunes which were not included in municipal Zones of Environmental Protection - ZPAs, using GIS tools and field studies. Natal has 46 remnants, most under great urban pressure, covering approximately $2.5 \%$ of its territory and distributed proportionally to the size of the administrative regions. Of these, 25 are in the vicinity and have similar characteristics of Zones of Environmental Protection - ZPAs, therefore should be incorporated. Actions to maintain this native ecosystem are necessary and urgent. To this end, recommendations were made for use and occupancy of each remnant as targets for urban and environmental planning.

Keywords: Urban Environmental Planning; Permanent Preservation Areas; Geoprocessing; Environmental Zoning; Management of Green Areas. 


\section{INTRODUÇÃO}

O município de Natal, capital do Rio Grande do Norte, é circundado por depósitos eólicos Quarternários, conhecidos como "dunas", constituindo campos de solo não consolidado proveniente de material quartzoso da plataforma continental. Os sedimentos constituintes são de areias de granulometria fina, bem selecionadas, de coloração esbranquiçada, amarelada e avermelhada, estando sobrepostos à Formação Barreiras (COSTA; SALIM, 1972; IDEC, 1989). Esses suprimentos de areias e formas de relevo são resultantes das sucessivas flutuações do nível do mar e de condições climáticas secas favoráveis à edificação das dunas alternadas com fase climática chuvosa ou úmida ideais à formação da cobertura vegetal, quimismo e pedogenização das areias dunares (GUERRA; CUNHA, 2005; IDEC, 1989). Estes campos dunares têm sua existência pela suposta ocorrência de várias gerações de deposições, cada uma dessas podendo representar importante modificação climática quaternária (SILVA, 2002).

Natal está situada numa zona de transição entre os tipos climáticos As` - quente e úmido, devido à elevada precipitação que o caracteriza, e BSh - semi-árido quente, devido à forte evaporação, segundo a classificação de Köppen (NOGUEIRA, 1981). Esses tipos de clima na região recebem influência das massas de ar advindas do Oceano Atlântico, constituídas de ventos alísios de direção SE-NW, que moldam as dunas em três feições morfológicas: as de lençol, língua e cordão. O lençol é a feição mais expressiva na paisagem de Natal, formada por agrupamentos de dunas sobrepostas ou interligadas, constituindo compartimentos de cristas e corredores dunares, com inclinação a barlavento mais suave do que a sotavento. A língua dunar é uma feição eólica de grandes áreas, limitada por encostas íngremes da superfície de aplainamento, com diversas cristas e cúpulas com altitudes entre 40 e 90 metros em relação ao nível do mar, de flancos com forte inclinação, mas suavemente arredondadas, fazendo frente à erosão causadas pelos ventos. Os cordões de dunas ocorrem em formas de "grampos de cabelo", com altura entre 10 e 30 metros, normalmente intercaladas por atividades antrópicas como retiradas de areais, terraplanagem e urbanização (IDEC, 1989). 
$\mathrm{Na}$ porção inicial da zona costeira de Natal, encontram-se as dunas móveis ou semifixas, que se mostram desnudas de cobertura vegetal ou com cobertura bastante rala, mal fixando o substrato, tornando este móvel sob a ação dos ventos alísios SE-NW. Mais para o interior do continente, a vegetação adensa-se sobre as dunas, formando as dunas fixas, imobilizadas sob a cobertura vegetal (RIZZINI, 1997). Esta é predominantemente composta por um complexo heterogêneo, com espécies de floresta atlântica, restinga e cerrado, sendo uma flora cosmopolita tropical, halófita e xerófila, com ocorrências de Bowdichia virgilioides (Sucupira), Cordia superba (Grão-de-galo), Stigmaphyllon paralias, Guettarda platypoda (Angélica), Coccoloba laevis (Cavaçu), Apuleia leiocarpa (Jitaí), Aechmea lingulata (Xinxo), Anacardium occidentale (Cajueiro) e Byrsonima gardneriana (Murici) (ALMEIDA JR. et al., 2009; RIZZINI, 1997). É uma comunidade adaptada à exposição contínua, a uma intensa radiação solar, a solos pobres em nutrientes e que, muitas vezes, estão sujeitas as ações antrópicas como pisoteio, corte e queimadas.

A fauna do Rio Grande do Norte é uma das menos conhecidas do nordeste brasileiro, por causa da ausência histórica de expedições científicas no Estado. Os poucos levantamentos existentes em dunas estão restritos a pequenas áreas e a obras de pouco acesso (e.g. FREIRE, 1996; VARELA-FREIRE, 1997; VARELA-FREIRE; ARAÚJO, 1997; VARELA-FREIRE; SILVEIRA, 1999; LISBOA, 2005). Apesar disso, os poucos estudos constatam uma importante biodiversidade, inclusive com espécies endêmicas como Coleodactylus natalensis, um lagartinho-de-folhiço endêmico dos remanescentes de Mata Atlântica do RN (FREIRE, 1996; LISBOA, 2008).

A zona de dunas é rica em água subterrânea, com água doce em até 1-2m da superfície (RIZZINI, 1997). As dunas da Grande Natal constituem importantes unidades de captação de águas pluviais para a recarga de aquíferos, utilizados para abastecer a população, sendo o principal deles o Aquífero Barreiras. Dentre os corpos de dunas mais expressivos, estão as Zonas de Proteção Ambiental - ZPAs 1 e 2. Embora esta última não contribua diretamente para a recarga, visto que a água que cai sobre ela segue em direção ao Oceano, ela auxilia na manutenção da qualidade das águas subsuperficiais em decorrência da formação de uma barreira hidráulica que contém o avanço subterrâneo da cunha salina em direção à terra, evitando a mistura das águas (JESUS, 2002). 
O município de Natal desenvolveu-se e teve sua expansão horizontal quase que sobreposto às dunas e, até a década de 1970, não se observava um crescimento tão acentuado na cidade, que vêm se verticalizando rapidamente. O planejamento ambiental e urbanístico da cidade visa, portanto, a garantir a qualidade de vida, resguardando os ecossistemas e demais áreas de preservação. A presença de fragmentos de vegetação natural de tamanho expressivo na malha urbana, como ocorre em Natal com as ZPAs, é condição rara nas cidades brasileiras. Tal característica faz de Natal uma cidade ímpar, pois tais áreas amenizam a temperatura, elevam a umidade relativa do ar na cidade (CARVALHO, 2001) e trazem grandes benefícios à população, além de manter a biodiversidade local se corretamente conservados. Os remanescentes de dunas do município que não estão integrados às ZPAs são fundamentais para a conservação dessas zonas, pois guardam metapopulações de espécies da flora e fauna nativas e garantem sua conectividade.

As dunas são consideradas Áreas de Preservação Permanente - APP, protegidas nos termos dos arts. $2^{\circ}$ e 3ำ do Código Florestal brasileiro e definidas segundo a Resolução no 303 do Conselho Nacional do Meio Ambiente - CONAMA, cobertas ou não por vegetação nativa, com função ambiental de preservar os recursos hídricos, a paisagem, a estabilidade geológica, a biodiversidade, o fluxo gênico de fauna e flora, proteger o solo e assegurar o bem-estar das populações humanas. Nessas áreas, não se pode fazer a retirada da cobertura vegetal original, permitindo, assim, que ela possa exercer, em plenitude, suas funções ambientais. A nãoobservância da legislação na prática decorre, basicamente, da inexistência da demarcação oficial das APPs para vetar, em seu nascedouro, o licenciamento ambiental indevido; e da constatação da deficiência estrutural do Estado, inviabilizando promover-se efetiva fiscalização ambiental em um país de dimensões continentais (RIBEIRO et al., 2005).

Diante do exposto, verifica-se que a duna é um ecossistema especialmente protegido, constituído por areias quartzosas que, quando depositadas pela ação do vento dominante, formam montes móveis que são posteriormente colonizados por plantas e animais típicos de regiões com baixo índice de pluviosidade. São excelentes reservatórios de água doce, sobretudo para a recarga dos aquíferos, uma vez que as águas pluviais que penetram no solo acumulam-se facilmente. Porosidade e permeabilidade altas permitem os usos dessas áreas 
como reservatórios naturais de recursos hídricos para a manutenção do meio natural e demais necessidades da população; entretanto, esse tipo de solo torna-as extremamente frágeis em áreas de adensamento urbano. Assim, este trabalho visa a identificar os remanescentes de dunas do Município do Natal, excluindo-se as que estão protegidas por ZPAs, por meio de mapeamento, caracterização das intervenções antrópicas e elaboração de estratégias de preservação e de uso e ocupação desse recurso natural característico do município de Natal.

\section{MATERIAIS E MÉTODOS}

A cidade de Natal está localizada na zona homogênea do Litoral Oriental do Rio Grande do Norte, entre os paralelos $36^{\circ} 42^{\prime} 53^{\prime \prime}$ e $37^{\circ} 15^{\prime} 11^{\prime \prime}$ de latitude sul e entre os meridianos $38^{\circ}$ $35^{\prime} 52^{\prime \prime}$ e $34^{\circ} 58^{\prime} 03^{\prime \prime}$ de longitude oeste. Abrange uma área total de 16.263,8 hectares e está subdividida nas regiões administrativas norte, sul, leste e oeste. Limita-se ao norte com 0 município de Extremoz, ao sul com os municípios de Parnamirim e Macaíba, a oeste com o município de São Gonçalo do Amarante, a leste com o Oceano Atlântico.

A delimitação das áreas de dunas foi realizada com base nos seguintes mapas em projeção UTM: Mapa IBGE do Estado do Rio Grande do Norte, escala 1:500.000; Mapa Geológico do Estado do Rio Grande do Norte, escala 1:500.000; Mapa de Unidades Fitoecológicas; Mapa de Uso Atual; Mapa IBGE de Zoneamento Geoambiental do Estado do Rio Grande do Norte em escala 500.000; Mapas Temáticos RADAMBRASIL dos Recursos Naturais, folhas SB. 24/25 Jaguaribe/Natal em escala 1:100.000. A partir desse documento, foram recolhidas assinaturas espectrais onde se identificavam as feições dunares. Então, utilizando-se de fotografia aérea vertical do ano de 2006 do município de Natal, delimitaram-se áreas semelhantes próximas às do mapa anterior. Pelas fotografias, foi possível avaliar parâmetros como textura e reflectância espectral dos alvos.

No geoprocessamento, foram utilizados os softwares ArcGIS, versão 9.2 da ESRI, e as versões 3.4 e 3.5 do software SPRING - Sistema de Processamento de Informações Georreferenciadas, desenvolvidos pelo Instituto Nacional de Pesquisas Espaciais - INPE. 
Utilizando-se de valores de cotas numéricas das curvas de nível obtidos por levantamento topográfico, foi criado um modelo digital de terreno como subsídio à identificação das dunas que se encontram na altitude de 30 até 70 metros do nível do mar, com declividade acima de $40 \%$. Um perfil topográfico foi elaborado a partir das curvas de nível da Prefeitura Municipal do Natal elaboradas no ano de 2006. Essa ferramenta demonstra o corte vertical da duna, permitindo observar a sua declividade.

Foram realizadas visitas in loco em cada uma das áreas mapeadas, ao longo do ano de 2008, para confirmação, diagnóstico e cadastramento das mesmas áreas no software de SIG, seguidas da confecção de mapas e fichas individuais de mapeamento. As dunas foram classificadas em fixas, semifixas ou móveis, baseadas na presença ou não de vegetação, sendo essa caracterizada quanto ao seu grau de preservação. Na mesma ocasião, foram verificados os tipos de ocupação antrópica presentes, como habitações, pastagens, deposição de lixo, instalação de outdoors, dentre outras. Por fim, foram verificadas as condições de uso e ocupação do solo e os equipamentos urbanos presentes em cada área, a fim de subsidiar e elaborar estratégias de planejamento urbano e ambiental para as dunas em questão.

\section{RESULTADOS E DISCUSSÃO}

Foram mapeadas 104 áreas passíveis de serem dunas pelo SIG, baseando-se na reflectância espectral dos alvos identificados. Após visitação in loco, verificou-se que apenas 46 preservavam características de feição dunar (Figura 1), enquanto 58 não conservavam esse tipo de feição. 
Figura 1. Feições dunares identificadas no Município de Natal - RN

Figure 1. Dune features identified in Natal - RN, Brazil

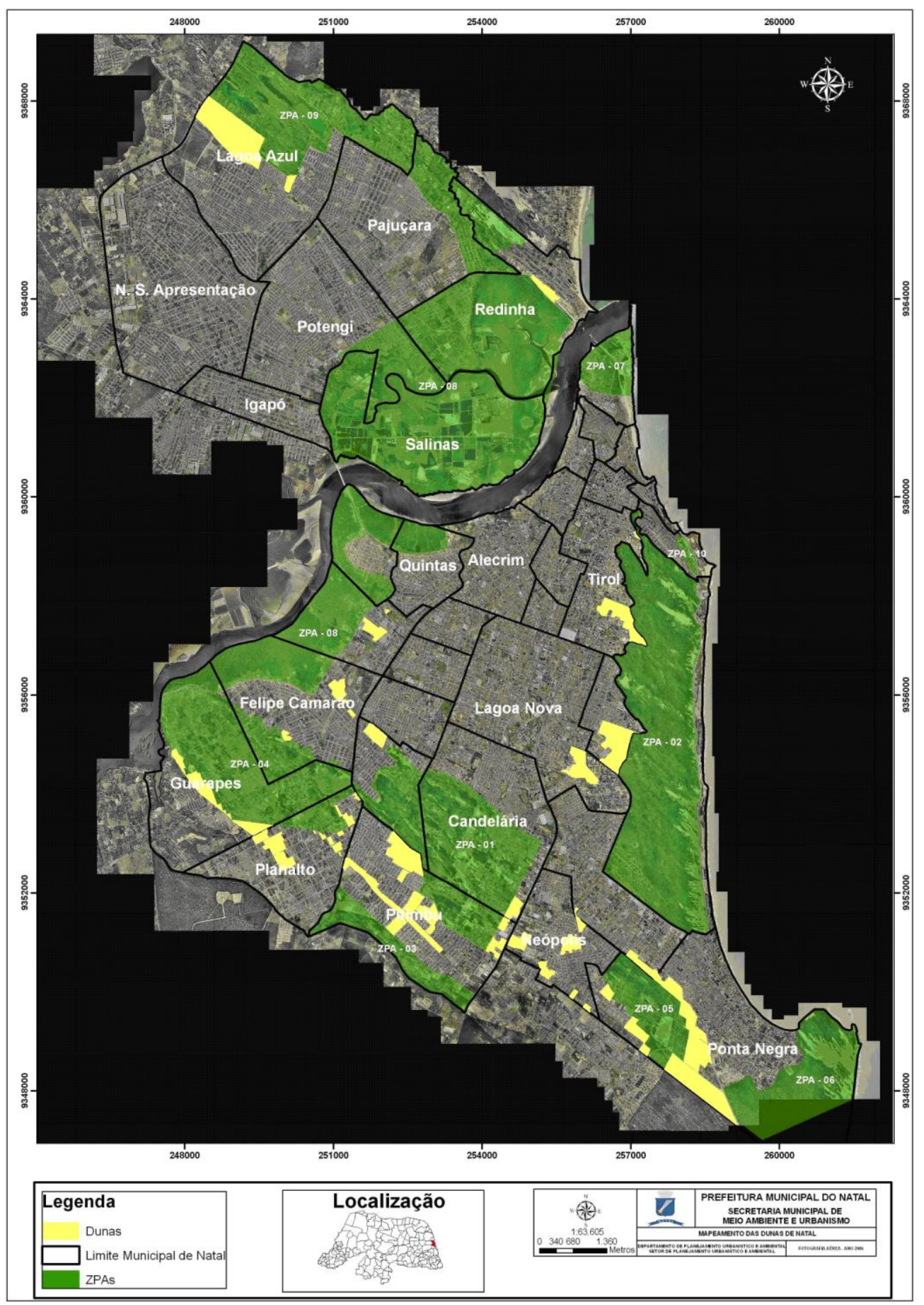


Para cada duna mapeada, foi elaborada uma ficha de identificação, conforme exemplo da Figura 2. Ao final do trabalho, foi elaborado um atlas cartográfico com todas as áreas, disponibilizado ao município para auxiliar nas ações de fiscalização ambiental.

Figura 2. Exemplo de ficha de identificação presente no atlas cartográfico das dunas do município de Natal - RN

Figure 2. Sample of identification form in the cartographic atlas of the dunes of Natal - RN

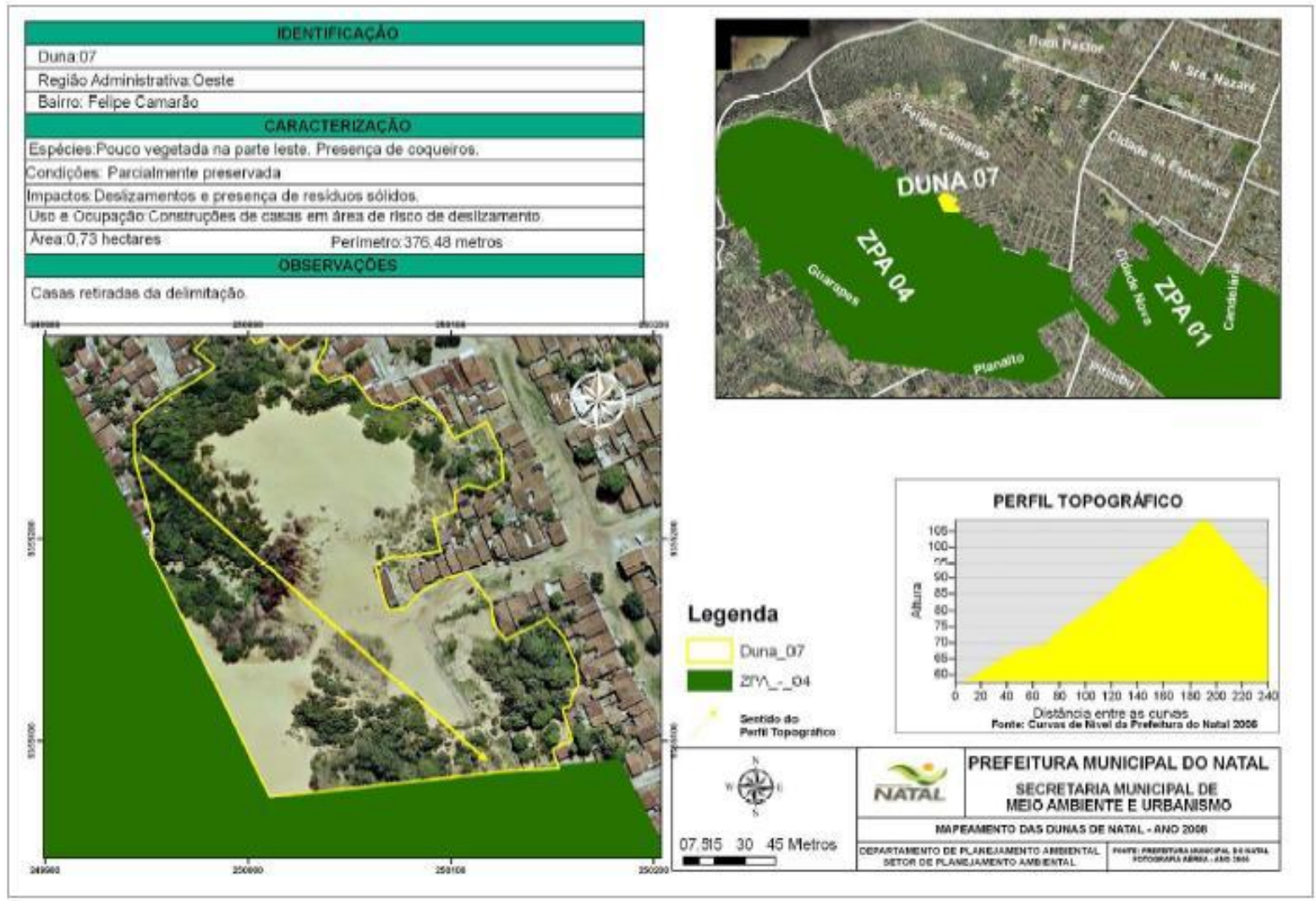

Verificou-se que Natal possui apenas 2,5\% de seu território composto por dunas preservadas não protegidas por ZPAs. As dunas mapeadas estão proporcionalmente distribuídas em relação à dimensão das regiões administrativas do município, conforme se observa na Tabela 1. 
Tabela 1. Áreas totais e proporções de remanescentes de dunas por região administrativa do município de Natal - RN

Table 1. Total areas and proportions of remnants of dunes by administrative region of Natal municipality, RN, Brazil

\begin{tabular}{llll}
\hline \multirow{2}{*}{$\begin{array}{lll}\text { REGIÃO } \\
\text { ADMINISTRATIVA }\end{array}$} & ÁREA TOTAL (ha) & \multicolumn{2}{l}{ ÁREA DE DUNAS PRESERVADAS } \\
\cline { 3 - 4 } & & $\begin{array}{l}\text { HECTARES } \\
\text { (ha) }\end{array}$ & $\begin{array}{l}\text { PORCENTAGEM } \\
(\%)\end{array}$ \\
\hline NORTE & $5.624,40$ & 110,00 & 1,96 \\
SUL & $5.762,50$ & 188,90 & 3,28 \\
OESTE & $3.408,40$ & 86,40 & 2,53 \\
LESTE & $1.468,50$ & 29,80 & 2,03 \\
TOTAL & $16.263,80$ & 415,10 & 2,55 \\
\hline
\end{tabular}

Do total de feições confirmadas como dunas, 13 são fixas, 31 são semifixas e duas são móveis. Em relação à vegetação, 15 possuem vegetação nativa bastante preservada; 16 possuem uma vegetação nativa pouco preservada associada a gramíneas e exóticas; e em três a vegetação nativa foi totalmente desmatada e sucedida por gramíneas.

Do total de dunas mapeadas, 25 estão no entorno de ZPAs e mantêm características semelhantes a elas (Figura 3). A fragmentação de habitats é uma das principais causas do declínio da biodiversidade no Brasil, causando desertificação e incremento da erosão de solo, vulnerabilidade dos habitats às alterações climáticas ou a extinção de espécies (PEREIRA et al., 2007). Sabe-se que fragmentos de mata maiores e com mais corredores de conexão têm maior capacidade de suporte à vida selvagem, uma vez que provêem mais espaço físico, mobilidade, segurança e alimentos à biodiversidade (CÂMARA, 1996; ZAÚ, 1998). Assim, a incorporação destes remanescentes às zonas de proteção é um aspecto fundamental para a sua manutenção e das próprias ZPAs. 
Figura 3. Quantitativo de remanescentes de dunas localizados no entorno de Zonas de Proteção Ambiental - ZPAs no município de Natal - RN, Brasil.

Figure 3. Quantitative of remnants of dunes in the vicinity of Zones of Environmental Protection - ZPAs in Natal - RN, Brazil.

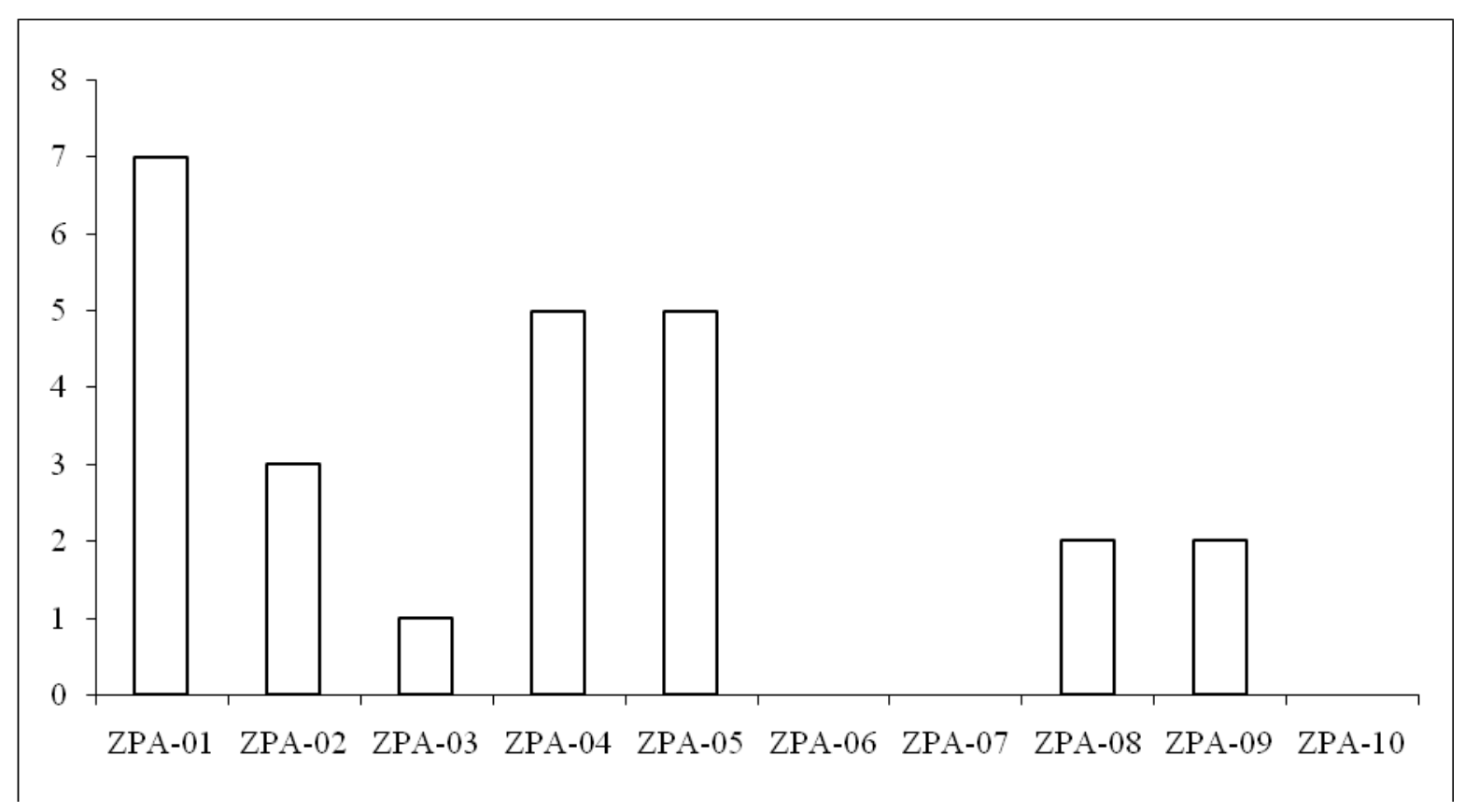

Os remanescentes de dunas em cada região administrativa do município foram caracterizados de acordo com sua condição geral de preservação, conforme a Figura 4. Verificou-se que, dos 46 remanescentes identificados, apenas nove apresentavam boas condições de preservação, onde não foram observados impactos ambientais, enquanto 37 encontravam-se parcialmente preservados. 
Figura 4. Condições de preservação dos remanescentes de dunas no município do Natal - RN por região administrativa

Figure 4. Situation of remnants of dunes in Natal, RN, Brazil, by municipal administrative region

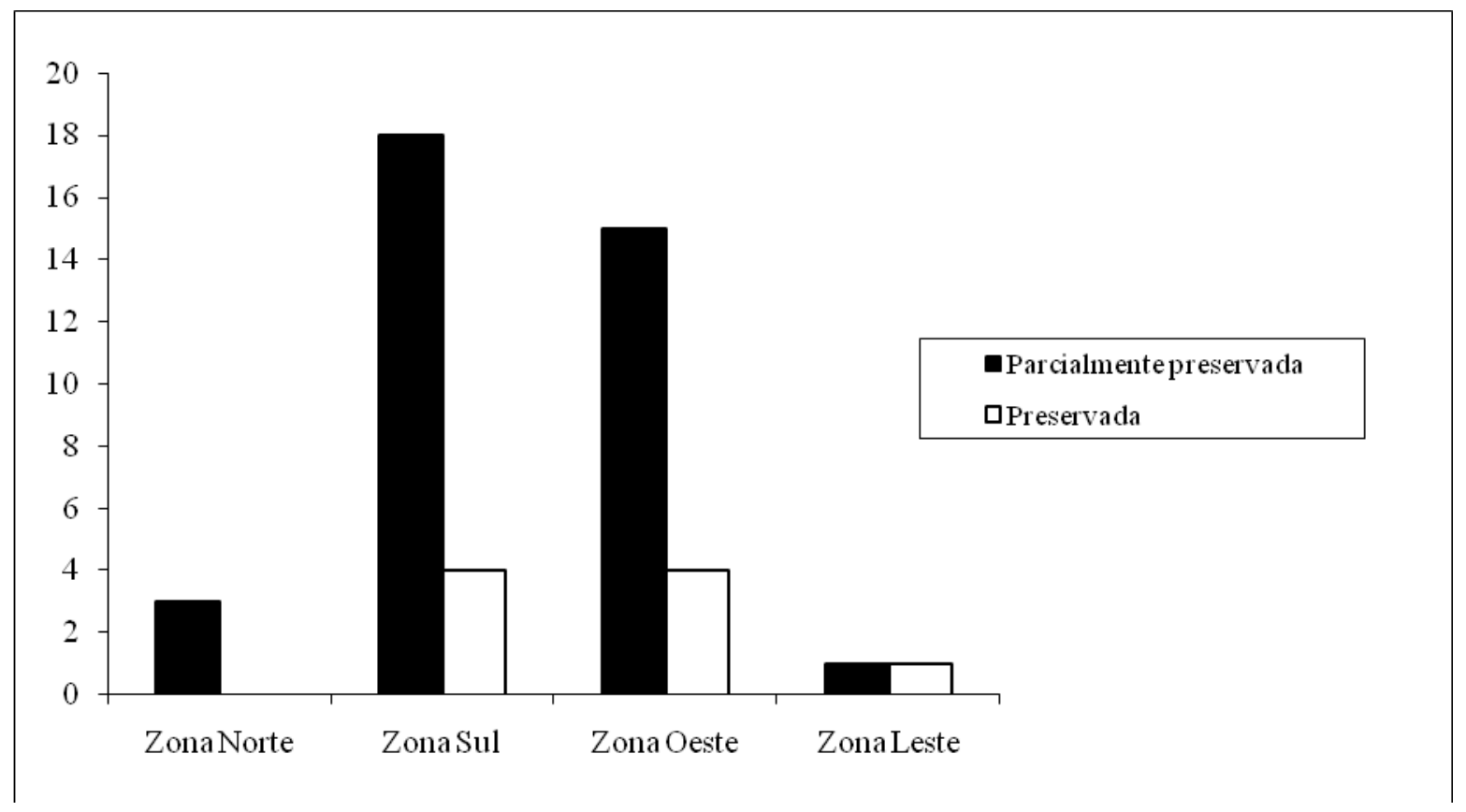

Em relação aos remanescentes parcialmente preservados, verificaram-se muitos impactos ambientais, como corte de feições para a construção de acessos, habitações ou até mesmo para o prolongamento da Ponte Newton Navarro; retirada de areia de sopés, juntamente com desmatamento da vegetação nativa, o que facilita a erosão do solo; e utilização de algumas áreas como locais de deposição de lixo oriundos principalmente da construção civil (Figura 5).

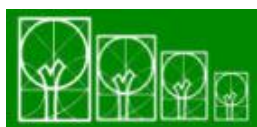


Figura 5. Impactos ambientais identificados nos remanescentes de dunas do município de Natal - RN, Brasil.

Figure 5. Environmental impacts identified in the remnants of dunes of Natal, RN, Brazil.

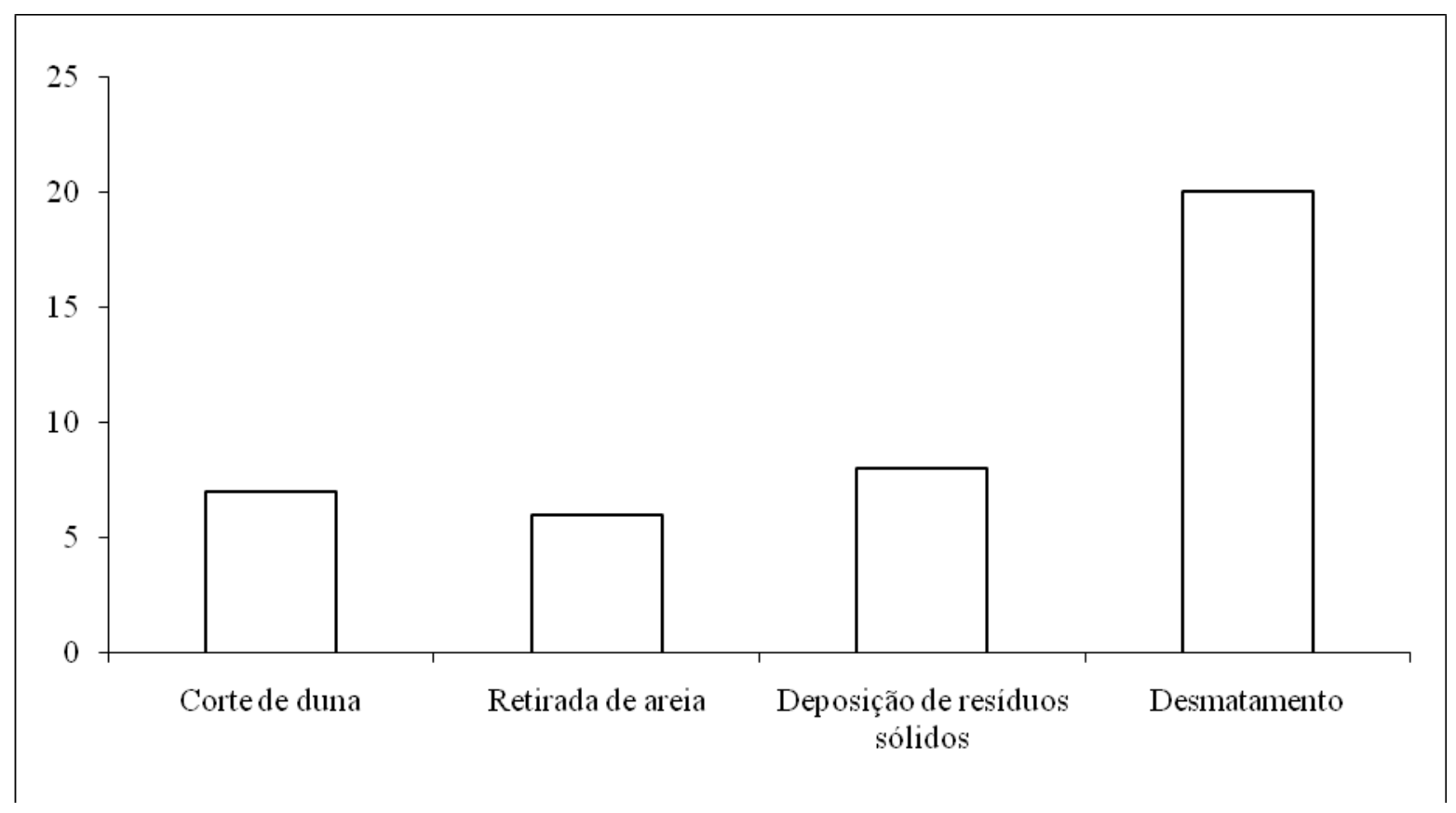

Há uma preocupante pressão imobiliária no entorno dessas 46 dunas, pois muitas se encontram ao redor de vários condomínios habitacionais em expansão, enquanto outras são colonizadas por habitações precárias. Em 30 desses remanescentes, constatou-se a presença de construções nos flancos laterais, cristas e sopés, aplainamento para construção de fundações, presença de equipamentos públicos e utilização como áreas verdes pela comunidade, distribuídos de acordo com a Figura 6. 
Figura 6. Uso e ocupação em remanescentes de dunas no município de Natal - RN

Figure 6. Use and occupation of remnants of dunes in Natal - RN, Brazil

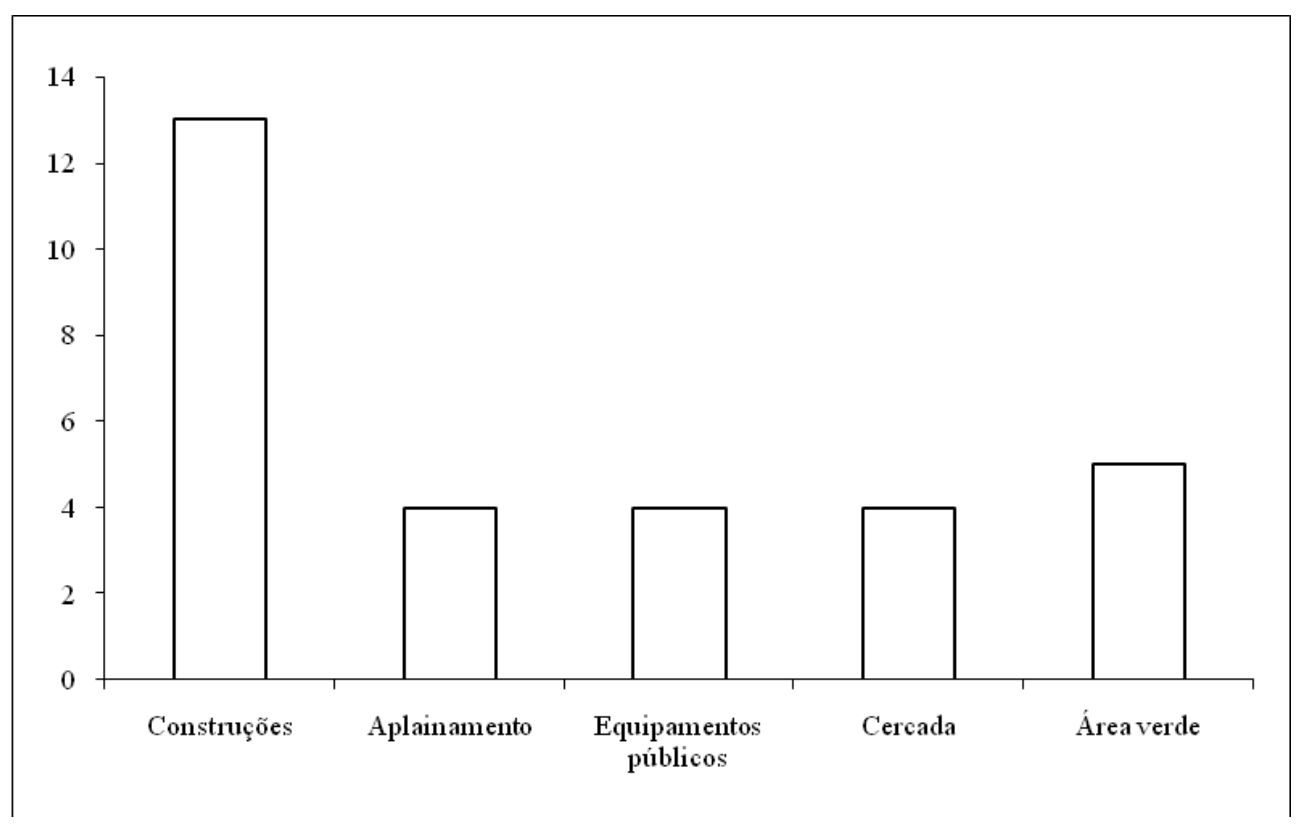

Observa-se, assim, que algumas das áreas estão ocupadas e/ou sujeitas à grande pressão de adensamento, fazendo que o comprometimento da feição seja evidente e, dessa forma, seja necessário sugerir atribuições de usos para essas áreas. Com o objetivo de elaborar estratégias de preservação e/ou de uso e ocupação dos remanescentes de dunas como metas de planejamento urbano e ambiental, foram elaboradas recomendações de uso para cada área, conforme Tabela 2.

Tabela 2. Recomendações de uso do solo para cada remanescente de dunas por Região Administrativa do Município de Natal - RN

Table 2. Land use recommendations for each of the remnants of dunes by Administrative Region of Natal - RN, Brazil

\begin{tabular}{llllll}
\hline REGIÃO & № DA & RECOMENDAÇÕES & & \\
ADMINISTRATIVA & DUNA & & \\
\hline NORTE & 1 & CONSERVAÇÃO, CRIAÇÃO DE PARQUE LINEAR. & \\
\hline NORTE & 13 & $\begin{array}{l}\text { CONSERVAÇÃO } \\
\text { LICENCIAMENTO (SE ÁREA PRIVADA). }\end{array}$ & & \\
\end{tabular}




\begin{tabular}{|c|c|c|}
\hline NORTE & 100 & CONSERVAÇÃO DA ÁREA DELIMITADA/ ANEXAR À ZPA-9. \\
\hline SUL & 2 & ANEXAR Ȧ ZPA-1. \\
\hline SUL & 4 & ANEXAR À ZPA-5. \\
\hline \multirow{2}{*}{ SUL } & \multirow{2}{*}{12} & ADENSAMENTO CONFORME \\
\hline & & EXISTENTE. \\
\hline SUL & 14 & CONSERVAÇÃO E INCORPORAÇÃO Ȧ ZPA-5. \\
\hline SUL & 15 & ADENSAMENTO. \\
\hline SUL & 16 & ADENSAMENTO. \\
\hline \multirow{2}{*}{ SUL } & \multirow{2}{*}{17} & CONSERVAÇÃO/ OCUPAÇÃO DA CAERN /AREA NON AEDIFICANDI/ \\
\hline & & INSCRIÇÃO DA PORÇÃO AO NORTE COMO ÁREA DE RISCO. \\
\hline SUL & 18 & CONSERVAÇÃO DO VALE NON AEDIFICANDI. \\
\hline \multirow{2}{*}{ SUL } & \multirow{2}{*}{22} & $\begin{array}{lllllll}\text { RECUPERAÇÃO } & \text { DA ÁREA } & \text { DEGRADADA } & \text { E } & \text { PRESERVAÇÃO/ÁREA } & \text { NON }\end{array}$ \\
\hline & & AEDIFICANDI. \\
\hline \multirow{2}{*}{ SUL } & \multirow{2}{*}{24} & RECUPERAÇÃO DA ÁREA DEGRADADA E PRESERVAÇÃO/ÁREA NON \\
\hline & & AEDIFICANDI. \\
\hline SUL & 41 & ANEXAR Ȧ ZPA-01/EQUIPAMENTO PÚBLICO. \\
\hline SUL & 43 & ÁREA DE RISCO/CONSERVAÇÃO/EQUIPAMENTO PÚBLICO/ÁREA VERDE. \\
\hline \multirow{2}{*}{ SUL } & \multirow{2}{*}{44} & RECUPERAÇÃO E CONSERVAÇÃO / CORREDOR ECOLÓGICO ZPA-1 E \\
\hline & & 3/PASSAGEM DA AV. PRUDENTE DE MORAIS. \\
\hline SUL & 45 & CONSERVAÇÃO/CORREDOR ECOLÓGICO /CAERN. \\
\hline \multirow{4}{*}{ SUL } & \multirow{4}{*}{46} & ÁREA ESPECIAL POR SER UM RELICTO DE TABULEIRO/ANEXAR À ZPA- \\
\hline & & 1/CONSERVAÇÃO COM RECUPERAÇÃO E RECOMPOSIÇÃO VEGETAL / \\
\hline & & PERMUTA COM O GOVERNO DO ESTADO/AMPLIAÇÃO DO HORTO \\
\hline & & MUNICIPAL. \\
\hline \multirow{2}{*}{ SUL } & \multirow{2}{*}{48} & ANEXAR À ZPA-5/ CONSERVAÇÃO DOS TABULEIROS E PRESERVAÇÃO DO \\
\hline & & CORDÃO DUNAR. \\
\hline SUL & 49 & CONSERVAÇÃO /CORREDOR ECOLÓGICO ZPA-5 - ZPA-6. \\
\hline SUL & 54 & CONSERVAÇÃO/ RETIRAR OCUPAÇÕES IRREGULARES. \\
\hline SUL & 85 & CONSERVAÇÃO/CAERN DE POTILÂNDIA \\
\hline \multirow{3}{*}{ SUL } & \multirow{3}{*}{91} & IRREGULARES \\
\hline & & /CONSERVAÇÃO/RECUPERAÇÃO DA ÁREA DEGRADADA/EQUIPAMENTO \\
\hline & & PÚBLICO NAS PARTES PLANAS. \\
\hline SUL & 101 & CONSERVAÇÃO/OCUPAÇÃO MILITAR \\
\hline \multirow{3}{*}{ SUL } & \multirow{2}{*}{130} & ANEXAR À ZPA-1 /PRESERVAÇÃO DA ÁREA DE INFLUÊNCIA DO VALE DUNAR \\
\hline & & E TRANSFERÊNCIA DO POTENCIAL CONSTRUTIVO. \\
\hline & & CONSERVAÇÃO/ÁREA DE RISCO/ REMOÇÃO/RECUPERAÇÃO/ NOVOS \\
\hline \multirow[t]{2}{*}{ OESTE } & \multirow[t]{2}{*}{5} & ESTUDOS E INTERVENÇÕES VISANDO A MINIMIZAR OS RISCOS E \\
\hline & & ESTABILIZAR A DUNA. \\
\hline
\end{tabular}




\begin{tabular}{|c|c|c|}
\hline OESTE & 6 & ADENSAMENTO. \\
\hline OESTE & 7 & CONSERVAÇÃO/RECUPERAÇÃO/ANEXAR Ȧ ZPA-4. \\
\hline \multirow{3}{*}{ OESTE } & \multirow{3}{*}{8} & CONSERVAÇÃO/ÁREA DE RISCO/REMOÇÃO/RECUPERAÇÃO/ NOVOS \\
\hline & & ESTUDOS E INTERVENÇÕES VISANDO A MINIMIZAR OS RISCOS \\
\hline & & ESTABILIZAR A DUNA. \\
\hline \multirow{2}{*}{ OESTE } & \multirow{2}{*}{28} & CONSERVAÇÃO/ÁREA \\
\hline & & NORDESTE/RECUPERAÇÃO/ ANEXAR À ZPA 4. \\
\hline \multirow{2}{*}{ OESTE } & \multirow{2}{*}{29} & GARANTIR A CONSERVAÇÃO DE FAIXA DE DOMÍNIO DE 10 METROS DA \\
\hline & & LINHA FÉRREA. \\
\hline \multirow{2}{*}{ OESTE } & \multirow{2}{*}{34} & ADENSAMENTO (SE ÁREA PRIVADA) /EQUIPAMENTO PÚBLICO (PRAÇA, SE \\
\hline & & ÁREA PÚBLICA). \\
\hline OESTE & 36 & CONSERVAÇÃO / ANEXAR Ȧ ZPA-4/RECUPERAÇÃO VEGETAL. \\
\hline \multirow{2}{*}{ OESTE } & \multirow{2}{*}{38} & $\begin{array}{lllllll}\text { CONSERVAÇÃO } & \text { E } & \text { INSTALAÇÃO } & \text { DE } & \text { EQUIPAMENTO } & \text { PÚBLICO } & \text { COM }\end{array}$ \\
\hline & & RECOMPOSIÇÃO VEGETAL (SE ÁREA PÚBLICA). \\
\hline OESTE & 73 & ADENSAMENTO. \\
\hline \multirow{2}{*}{ OESTE } & \multirow{2}{*}{75} & CONSERVAÇÃO/EQUIPAMENTO PÚBLICO (ÁREA VERDE) /RECOMPOSIÇÃO \\
\hline & & VEGETAL. \\
\hline OESTE & 76 & ADENSAMENTO. \\
\hline \multirow{2}{*}{ OESTE } & \multirow{2}{*}{$77 / 78$} & ADENSAMENTO COM RESTRIÇÕES (CONSERVAÇÃO DAS FEIÇÕES \\
\hline & & EXISTENTES, OBSERVANDO PLANO MUNICIPAL DE ARBORIZAÇÃO). \\
\hline OESTE & 79 & ADENSAMENTO. \\
\hline \multirow{4}{*}{ OESTE } & \multirow{4}{*}{99} & REMOÇÃO DE CASAS EM ÁREA DE RISCO/ PRESERVAÇÃO DA ÁREA DE \\
\hline & & DOMÍNIO DA REDE ELÉTRICA/ RECOMPOSIÇÃO VEGETAL PARA ESTABILIZAR \\
\hline & & ENCOSTAS/AMPLIAÇÃO DO CEMITÉRIO DO BOM PASTOR NA ÁREA PLANA \\
\hline & & AO LESTE. \\
\hline \multirow{3}{*}{ OESTE } & \multirow{3}{*}{104} & ADENSAMENTO COM RESTRIÇÕES (REGULARIZAÇÃO FUNDIÁRIA DAS \\
\hline & & ÁREAS PLANAS /CONSERVAÇÃO DAS FEIÇÕES EXISTENTES, PODENDO \\
\hline & & FAZER PARTE DE UM PLANO MUNICIPAL DE ARBORIZAÇÃO). \\
\hline OESTE & 105 & ADENSAMENTO. \\
\hline \multirow{2}{*}{ OESTE } & \multirow{2}{*}{106} & EQUIPAMENTO PÚBLICO (SE ÁREA PÚBLICA) / ADENSAMENTO (SE ÁREA \\
\hline & & PRIVADA). \\
\hline \multirow{2}{*}{ OESTE } & \multirow{2}{*}{108} & ADENSAMENTO (SE ÁREA PRIVADA)/EQUIPAMENTO PÚBLICO (PRAÇA, SE \\
\hline & & ÁREA PÚBLICA). \\
\hline LESTE & 80 & RECOMPOSIÇÃO VEGETAL/CONSERVAÇÃO. \\
\hline LESTE & 102 & CONSERVAÇẪO, COM OCUPAÇÃO DA SEDE DO IDEMA. \\
\hline
\end{tabular}

\section{CONCLUSÕES}

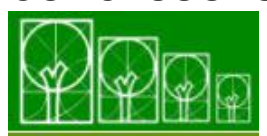

S · B $\cdot \mathbf{A} \cdot \mathbf{U}$ Soc. Bras. de Arborização Urbana 
Nesse estudo, constatou-se que o município de Natal possui 46 remanescentes de dunas, sendo três na região administrativa Norte, 22 na Sul, 19 na Oeste e duas na Leste. Verificou-se que muitos desses, além de constituírem solos de grande valor para a manutenção do aquífero, compõem habitats importantes para a manutenção das populações de espécies nativas da cidade, inclusive para a conservação de espécies endêmicas ou ameaçadas de extinção. A vegetação remanescente nas dunas mapeadas serve de testemunho da biodiversidade original e pode ser utilizada como matriz para a recuperação ou restauração de áreas verdes do município com as espécies originais.

Muitos dos remanescentes estão localizados no entorno de ZPAs municipais, portanto, sugere-se uma revisão e/ou regulamentação para que estas dunas sejam incorporadas e, consequentemente, melhor geridas e protegidas.

Verificou-se uma intensa pressão imobiliária, especialmente sobre os remanescentes localizados no entorno da ZPA-5, uma área frágil que apresenta características ambientais que justificam a sua proteção, sendo necessárias intervenções urgentes e imediatas do poder público.

Este estudo é preliminar e necessita de uma avaliação mais aprofundada sobre a situação dos remanescentes de dunas de Natal, com a participação das Secretarias Municipais no desenvolvimento de ações que visem a dar suporte à identificação de habitações em situação de risco ambiental e a intervenções para recuperação de áreas degradadas.

Por fim, este estudo evidencia a importância da conservação dos remanescentes de dunas do município para o bem-estar da cidade de Natal, devendo resultar em ações restauradoras que não coloquem em risco o ecossistema nativo, mantenham a integridade genética das populações, impliquem rápida recuperação da vegetação das dunas e capacidade de sustentabilidade desses ecossistemas reconstituídos.

\section{REFERÊNCIAS BIBLIOGRÁFICAS}

ALMEIDA JR., E.; ZICKEL, C.; PIMENTEL, R. Caracterização e Espectro Biológico da Vegetação do Litoral Arenoso do Rio Grande do Norte. Revista de Geografia, v. 23, n. 3, p. 6686, 2009.

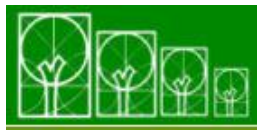

S $\cdot \mathbf{B} \cdot \mathbf{A} \cdot \mathbf{U}$ Soc. Bras. de Arborização Urbana 
CÂMARA, I.G. Plano de ação para a Mata Atlântica. Roteiro para a conservação de sua biodiversidade. Série Cadernos da Reserva da Biosfera, Caderno n4, São Paulo, 1996. 34 p. Disponível em: <http://www.cprh.pe.gov.br/rbma/downloads/CadernosRB/n4.pdf>. Acesso em: 16 dez. 2010.

CARVALHO, M. M. Clima urbano e vegetação: estudo analítico e prospectivo do Parque das Dunas em Natal. Natal, 2001. 278 f. Dissertação (Mestrado) - Universidade Federal do Rio Grande do Norte.

COSTA, W.D.; SALIM, J. Aspectos estruturais da faixa sedimentar costeira da região de Natal RN. Revista de Estudos Sedimentológicos, v.2, n 1⁄2, p.133-143, 1972.

FREIRE, E. M. X. Estudo ecológico e zoogeográfico sobre a fauna de lagartos (Sauria) das dunas de Natal, Rio Grande do Norte e da restinga de Ponta de Campina, Cabedelo, Paraíba, Brasil. Revista Brasileira de Zoologia, v.13, n.4, p.903-921, 1996.

GUERRA, A. J. T.; CUNHA, S. B. Geomorfologia - uma Atualização de Bases e Conceitos. 6. ed. Rio de Janeiro: Ed. Bertrand Brasil, 2005.

IDEC - FUNDAÇÃO INSTITUTO DE DESENVOLVIMENTO DO NORDESTE. Perfil ambiental das dunas no município de Natal - RN e de outras áreas de relevante interesse especial. Natal, 1989.

JESUS, A. P. Caracterização Geológica, Geomorfológica e Geotécnica de um Corpo de Dunas na Cidade de Natal-RN. 2002. 214 f. Dissertação (Mestrado) - Universidade Federal do Rio Grande do Norte, Natal.

LISBOA, C. M. C. A. Diversidade e distribuição espacial dos Squamata do Parque Estadual das Dunas do Natal-RN: avaliação pretérita e atual. Natal, 2005. $27 \mathrm{f}$. Trabalho de Conclusão de Curso (Graduação) - Centro de Biociências, Universidade Federal do Rio Grande do Norte. 
LISBOA, C. M. C. A. Estrutura da população de Coleodactylus natalensis Freire, 1999 (Squamata: Sphaerodactylidae) no Parque Estadual das Dunas do Natal, Rio Grande do Norte, Brasil. Natal, 2008. 61 f. Dissertação (Mestrado) - Centro de Biociências, Universidade Federal do Rio Grande do Norte.

NOGUEIRA, A. M. B. O cenozóico continental na região de Natal-RN. Boletim do Departamento de Geologia, Natal, p.15-24, 1981.

PEREIRA, M. A. S.; NEVES, N. A. G. S.; FIGUEIREDO, D. F. C. Considerações sobre a Fragmentação Territorial e as Redes de Corredores Ecológicos. Geografia, Departamento de Geociências, Universidade Estadual de Londrina, v. 16, n. 2, 2007.

RiBEIRO, C. A. A. S.; SOARES, V. P.; OlIVEIRA, A. M. S.; GLERIANI, J. M. O Desafio da Delimitação de Áreas de Preservação Permanente. Revista Árvore, Viçosa-MG, v. 29, n. 2, p. 203-212, 2005.

RIZZINI, C. T. Tratado de Fitogeografia do Brasil: aspectos ecológicos, sociológicos e florísticos. 2. ed. São Paulo: Âmbito Cultural, 1997.

SILVA, E. A. J. As dunas eólicas de Natal/RN: Datação e evolução. Natal, 2002. $127 \mathrm{f}$. Dissertação (Mestrado), Universidade Federal do Rio Grande do Norte.

VARELA-FREIRE, A. A. A Fauna do Litoral Oriental e do Parque Estadual das Dunas Costeiras do Natal. 1. ed. Natal: EDUFRN, 1997.

VARELA-FREIRE, A. A.; ARAÚJO, S. A. Zoogeografia do Rio Grande do Norte I. A Ornitofauna do Seridó Potiguar. Caderno Norte-Riograndense de Temas Geográficos, Natal-RN, v. 11, n. 1, p. 52-81, 1997.

VARELA-FREIRE, A. A.; SILVEIRA, A. G. Lista Atualizada das Aves do Estado do Rio Grande do Norte. SEPLAN/IDEMA, Natal: EDUFRN, 1999. 
ZAÚ, A. S. Fragmentação da Mata Atlântica: aspectos teóricos. Floresta e ambiente, Rio de Janeiro, v.5, n. 1, p. 166-170, 1998. 